\title{
Interference of partial visual analysis of root filling quality and apical status on retreatment decisions
}

\author{
Renata Dornelles MORGENTALํ, Régis Burmeister dos SANTOS², Cassiano Kuchenbecker RÖSING³ , Taís do Amaral \\ CHANIN $^{4}$, José Antônio Poli de FIGUEIREDO 5
}

\author{
1- DSS, MSc, PhD student in Endodontics, Pontifical Catholic University of Rio Grande do Sul, Porto Alegre, RS, Brazil. \\ 2- DDS, MSc, PhD, Full Professor of Endodontics, Federal University of Rio Grande do Sul, Porto Alegre, RS, Brazil. \\ 3- DDS, MSc, PhD, Associate Professor of Periodontics, Federal University of Rio Grande do Sul, Porto Alegre, RS, Brazil. \\ 4- DDS, Dentist, Brazilian Navy, Rio Grande, RS, Brazil. \\ 5- DDS, MSc, PhD, Head of the Post-graduate Program in Dentistry, Pontifical Catholic University of Rio Grande do Sul, Porto Alegre, RS, Brazil.
}

Corresponding address: Renata Dornelles Morgental, Av. Itaqui 71/201 - 90460-140 - Porto Alegre - RS - Brazil - Phone: +55 5133318204 - e-mail: remorgental@hotmail.com

Received: June 04, 2010 - Modification: August 26, 2010 - Accepted: October 26, 2010

\section{ABSTRACT}

O bjective: The presence of periapical radiolucency has been used as a criterion for endodontic treatment failure. However, in addition to the inherent limitations of radiographic examinations, radiographic interpretations are extremely subjective. Thus, this study investigated the effect of partial analysis of root filling quality and periapical status on retreatment decisions by general dentists. Material and Methods: Twelve digitalized periapical radiographs were analyzed by 10 observers. The study was conducted at three time points at 1-week intervals. Radiographs edited with the Adobe Photoshop CS4 software were analyzed at three time points: first, only root filling quality was analyzed; second, only the periapical areas of the teeth under study were visualized; finally, observers analyzed the unedited radiographic image. Spearman's coefficient was used to analyze the correlations between the scores assigned when the periapical area was not visible and when the unedited radiograph was analyzed, as well as between the scores assigned when root fillings where not visible and when the unedited radiograph was analyzed. Sensitivity, specificity, positive and negative predictive values between partial images and unedited radiographs were also used to analyze retreatment decisions. The level of significance was set at $5 \%$. Results: The visualization of the root filling on the unedited radiograph affected the interpretation of the periapical status and the technical quality of the fillings has a greater influence on the general dentist's decision to prescribe endodontic retreatment than the periapical condition. Conclusion: In order to make endodontic diagnosis, radiographic interpretation process should not only emphasize technical aspects, but also consider biological factors.

Key words: Diagnostic. Periapical diseases. Radiography. Root canal obturation.

\section{INTRODUCTION}

The potential methods to evaluate results of endodontic treatment are clinical signs and symptoms, radiographic findings and histological studies $^{7,16,19}$. Clinical signs are infrequent and periapical biopsies are difficult to obtain, but changes in periapical tissues after endodontic treatment are usually detected on radiographs ${ }^{12,23}$.

The development or persistence of periapical radiolucencies on postoperative follow-up radiographs is a usual sign of root canal treatment failure ${ }^{13-14}$. The wide variation in success and failure rates in studies that report on results of endodontic treatment may be at least partly explained by interobserver variation during radiographic analysis ${ }^{21}$.

Several studies have shown that the poor quality of root fillings may lead to endodontic failure. An inadequate apical seal and the presence of empty spaces between filling material and canal walls may also increase chances of unsuccessful treatment ${ }^{6}$. Adequate root fillings are associated with a lower prevalence of periapical disease ${ }^{5}$. However, high-quality root fillings do not prevent the penetration of bacteria and their byproducts when coronal restorations are not adequate ${ }^{15}$. Moreover, radiographs alone do not provide a complete evaluation of the efficiency of root canal 
cleaning, which is fundamental for treatment success ${ }^{2,26}$.

With regard to the reliability of conventional buccolingual radiographs to evaluate the technical quality of endodontic treatment, a defective seal might be misclassified as adequate when root canals are oval. In addition, the large amount of tissue surrounding molars might cause great variations in radiographic interpretation ${ }^{8}$. Different sealers, regarding their radiopacity, could influence the radiographic perceptions of laterally condensed root canal fillings ${ }^{4}$.

The effect of inter- and intraobserver variation in radiographic assessment of endodontic treatment results was studied previously ${ }^{23}$. Endodontists and radiologists evaluated periapical status and root filling quality in intraoral radiographs. A consensus on the presence of periapical lesions was found in only $27 \%$ of the cases. The most difficult diagnosis to reproduce, considering the same observer, was widened periodontal ligament space. The same study showed that the technical quality of root fillings may affect the radiographic diagnosis of periapical diseases. Observers tend to classify the periapical status as diseased when sealing is defective.

Several authors investigated differences in prescribing endodontic retreatment among general dentists ${ }^{1,3,18,25}$. General dentists recommend retreatment based on two main criteria: the presence of periapical radiolucency and planned prosthodontic treatment ${ }^{20}$. Variations in radiographic interpretations of endodontically treated teeth may lead to different treatment plans ${ }^{18}$.

During retreatment decisions, it is important to consider the complexity of the radiographic interpretation process and the technical and biological aspects involved. For example, if a periapical lesion can be identified, there is probably a tendency of worsening the quality score of a root filling as compared to when no lesion is seen. Therefore, this study investigated differences in radiographic evaluations of the quality of root fillings and periapical status when analyzed separately and in combination, and the differences between general dentists when deciding whether or not to prescribe endodontic retreatment. The hypothesis to be tested in the present study is that masking the examiner to the whole content of a radiograph could lead to different diagnostic and treatment approaches.

\section{MATERIAL AND METHODS}

\section{Selection of radiographs}

Twelve periapical radiographs were selected from the files of the Advanced Course in Endodontics of Dental School at Federal University of Rio Grande do Sul (UFRGS), Brazil. Radiographs were included if they showed one endodontically treated tooth and had good radiographic quality (adequate definition and density). No restrictions were made according to type of tooth.

\section{Radiograph digitalization}

Radiographs were digitalized using a digital camera DSC-H50 Cyber-Shot (Sony Corp., Tokyo, Japan) in a slightly dimmed room. Radiographs were placed on conventional x-ray boxes (white light) and photographed. A mask was used to reduce excessive lighting because the radiograph was smaller than the $\mathrm{x}$-ray box display.

\section{Radiograph edition}

Digitalized images were enlarged 3 times to simulate the use of a magnifying glass during radiographic interpretation. Adobe Photoshop CS4 software (Adobe Systems Inc., San Jose, CA, USA) was used for that purpose. Original brightness and contrast were preserved and reproduced as faithfully as possible.

After digitalization, images were edited using the same software. First, the periapical area of the tooth to be evaluated was covered using the black paintbrush tool (Figure 1). Second, the white paintbrush tool was used to remove the tooth image from the original radiographic image (Figure 2 ).

\section{Radiographic interpretation}

The digitalized radiographs were exhibited on a 15" notebook monitor (Acer Inc., Taipei, Taiwan) and examined by 10 general dentists, who had previously received a letter explaining the study and had signed an informed consent term to participate in the study. This study was approved by the Research Ethics Committee of Dental School of the Federal University of Rio Grade do Sul, Brazil (protocol number 03/06).

Radiographic interpretations were conducted at

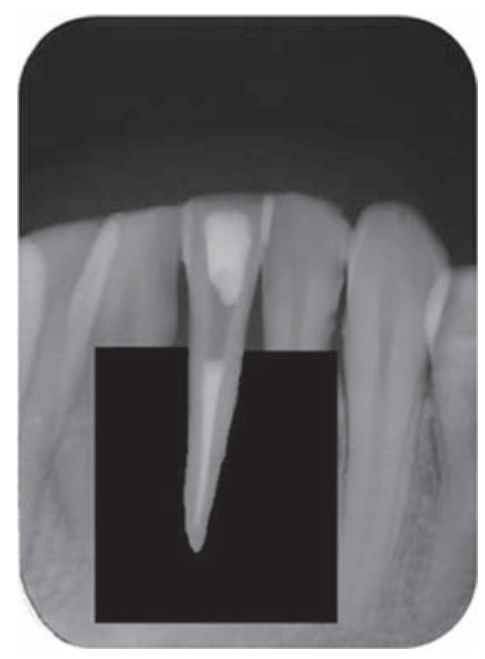

Figure 1-Analysis I (only fillings are visible) 


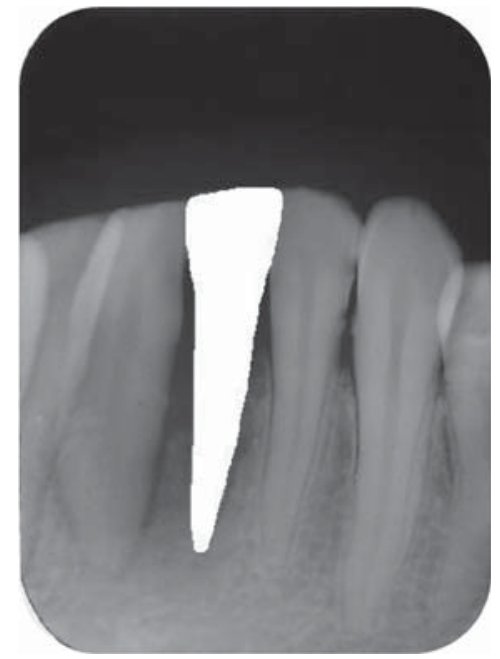

Figure 2- Analysis II (only periapical areas are visible)

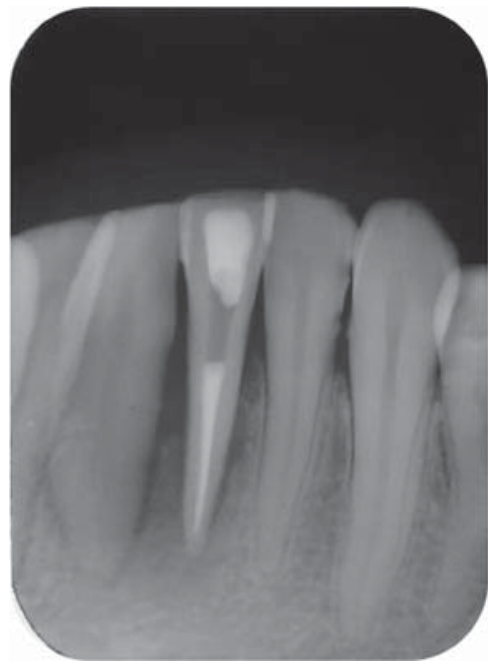

Figure 3- Analysis III (unedited radiograph)

Table 1- Spearman's correlation coefficient ( $r$ ) between scores assigned to partial or complete radiographic image analysis

\begin{tabular}{lcc}
\hline & $\mathbf{r}$ & $\mathbf{P}$ \\
\hline Filling quality & 0.815 & 0.000 \\
Periapical score & 0.586 & 0.000 \\
Retreatment indication (filling vs. unedited radiograph) & 0.730 & 0.000 \\
Retreatment indication (periapical area vs. unedited radiograph) & 0.284 & 0.006 \\
\hline
\end{tabular}

three time points at 1 -week intervals. The image sequence was random, and images were coded for later comparisons. The first images evaluated were the ones that only provided information about the technical quality of root fillings (Figure $1)$. At the second time point, only the periapical areas were analyzed (Figure 2). At the third time point, observers evaluated the complete, unedited radiographic image (Figure 3 ).

General dentists that participated in the study received a questionnaire to classify radiographic images according to pre-established criteria. The periapical area was classified as normal, widened periodontal ligament space or periapical radiolucency. Filling quality, considering apical seal and density, was classified as good, fair or poor. After that, general dentists stated whether they would recommend retreatment based on their observations.

\section{Statistical analysis}

The evaluation of unedited radiographic images was the reference test. Spearman correlation coefficients were calculated between the scores assigned to root fillings when the apical area was not visible and when the unedited radiographic image was analyzed, and between the apical scores when the tooth was not visible and the unedited radiographic image was analyzed. The prescription of retreatment was analyzed using the Spearman's correlation coefficient between the scores assigned to the root filling or periapical status and the corresponding scores of unedited radiographic images. Sensitivity, specificity, positive and negative predictive values between partial and complete radiographic images were used to analyze retreatment decisions. The level of significance was set at $5 \%$.

\section{RESULTS}

Table 1 shows the Spearman's correlation coefficients found for the partial analyses of filling quality (analysis I) and periapical status (analysis II) in comparison with the "reference" values (analysis III). It also shows the analysis of retreatment prescription when using partial or complete radiographic analysis. Statistically significant values $(p<0.05)$ were found for all correlations, and the highest coefficient was found between filling quality evaluated alone and the unedited radiographic image analysis. The analysis of retreatment prescription showed that the evaluation of root filling alone had a greater correlation than the analysis of periapical area alone when compared with the unedited radiographic image scores.

The validation of partial analysis in comparison with the "reference" for retreatment decisions is presented in Table 2. The partial analysis of fillings had greater sensitivity, specificity, positive and negative predictive values than the periapical 
Table 2- Sensitivity, specificity, positive and negative predictive values for retreatment decisions according to partial root filling or periapical evaluations compared with the analysis of unedited radiographic images

\begin{tabular}{lcc}
\hline & $\begin{array}{c}\text { Analysis of filling vs. unedited } \\
\text { radiograph }\end{array}$ & $\begin{array}{c}\text { Analysis of periapical area vs. unedited } \\
\text { radiograph }\end{array}$ \\
\hline Sensitivity & & 0.6 \\
Specificity & 0.8 & 0.69 \\
PPV & 0.96 & 0.78 \\
NPV & 0.97 & 0.48 \\
\hline
\end{tabular}

evaluation alone.

\section{DISCUSSION}

Several studies have investigated inter- and intraobserver variations in the radiographic evaluation of endodontically treated teeth $17,21,23,26$. According to Whaites ${ }^{27}$ (2002), radiographic images have limited information in the form of different shadows. To complete the scenario, dentists fill in the gaps, but they do not all necessarily do this in the same way and may arrive at different conclusions. In addition, the environment or context in which we see an image can affect how we interpret that image.

This study evaluated the interpretation of filling quality and periapical status alone and, after that, to compare findings with the analysis of complete, unedited radiographic images. Therefore, this experimental study was conducted with observations at 1-week intervals. The purpose of this interval, together with the number of images and the sequence randomization, was to ensure that observer's answers were not affected by memories of the scores previously assigned.

The comparison of scores assigned to root fillings and unedited radiographs had a greater Spearman's correlation coefficient $(0.815)$ than the one for the comparison between periapical area and unedited radiographs $(0.586)$. This finding indicates that the visualization of the filling on the unedited radiographic image affected the interpretation of periapical status. This finding is in agreement with those reported by Reit and Hollender ${ }^{23}$ (1983). They suggested that the observer tends to misclassify the periapical condition as pathological when the canal has a defective filling.

When the decisions about retreatment were compared between analysis I (filling quality) and analysis III (unedited radiographic images), the Spearman's correlation coefficient was 0.730 , substantially greater than the coefficient found for the comparison of analysis II (periapical status) and analysis III (unedited radiographic image), which was 0.284 . These data show that the technical quality of the fillings had a greater influence on the general dentist's decision to prescribe endodontic retreatment than the periapical status. However, according to Lin, Skribner and Gaengler ${ }^{10}$ (1992), the radiographic appearance of an adequately filled root canal does not ensure that it is adequately clean and completely filled. Radiographs do not provide three-dimensional images, and spaces that are not visible may become niches for microorganisms ${ }^{19}$.

An important factor for the analysis of a diagnostic test is the choice of a "reference group", for comparisons ${ }^{11,24}$. In this study, the unedited radiographic images were the "reference group" because they provided more information; moreover, unedited images are frequently used as evaluation tools. Sensitivity, specificity, positive and negative predictive values for retreatment indication were calculated using this criterion.

In this study, sensitivity corresponded to the capacity of the partial radiographic analysis (analysis I or II) to detect the need for retreatment according to the unedited radiographic image analysis (analysis III). Results showed that the analysis of fillings (0.80) was more sensitive than the analysis of the periapical area (0.60) for decisions about endodontic retreatment.

Specificity, the capacity of the partial radiographic analysis (analysis I or II) to rule out the need for retreatment when actually not recommended according to the unedited radiographic image analysis (analysis III), showed that the analysis of fillings (0.96) was more specific than the periapical analysis (0.69) to rule out retreatment.

The positive predictive value (PPV) indicated the percentage of teeth for which retreatment was prescribed in partial analysis and which actually needed retreatment according to the analysis of unedited radiographic images. Results showed that, once retreatment was prescribed based on the analysis of fillings (analysis I), the probability of this prescription being correct was 97\% (PPV=0.97), whereas for the analysis of periapical area (analysis II), this probability was $78 \%(P P V=0.78)$.

The negative predictive value (NPV) indicated the percentage of teeth for which retreatment was not prescribed in partial analysis and that actually did not need retreatment according to the analysis 
of unedited radiographic images. The values found indicated that, once retreatment was ruled out in the analysis of fillings (analysis I), the probability of retreatment being actually unnecessary was $71 \%$ $(N P V=0.71)$. In the analysis of the periapical area (analysis II), however, this value was only $48 \%$ $(\mathrm{NPV}=0.48)$.

The determination of endodontic treatment success should be based on clearly defined criteria, such as clinical and radiographic findings ${ }^{9}$. One of the limitations of this study was that only the radiographic analysis was used to evaluate the need for retreatment. According to the observers, the major aspects to be observed for decision making, in addition to radiographic evaluation, were: time for completion of endodontic treatment, the tooth's clinical condition (symptoms and quality of coronal sealing), and the need to use a post and prosthetic crown. However, radiographic examination is often used alone, which, according to the findings reported here, is potentially inadequate.

Different approaches are available to treat periradicular lesions that are refractory to conventional treatment. Radiographic followup, root canal retreatment, endodontic surgery and replacement with an implant are the main options. Great variations are found among general dentists when deciding about the most appropriate treatment $3,18,22,28$.

Retreatment is definitely indicated when periapical radiolucency is accompanied by clinical signs or symptoms. However, where there is no evidence of periapical disease or clinical indications, the case should be followed up radiographically even if root canal filling is not ideal ${ }^{25}$.

Al-Ali, et al. ${ }^{1}$ (2005) found that, when general dentists prescribed retreatment for a periapical lesion of a particular size, then they would recommend retreatment for all larger lesions. However, there is significant variation among general dentists in the choice of a threshold to prescribe retreatment. The results of this study showed that the analysis of isolated factors may affect retreatment decisions. However, longitudinal follow-up studies of clinical and radiographic characteristics that predict the progression of periapical lesions are still scarce and inconclusive.

Results of this study have a challenging clinical implication: current diagnostic resources should be used in combination to make the best possible decision. Radiographs that provide unclear visualization either of root filling or periapical area may often lead to misdiagnoses. In addition to radiographs, clinical history and other characteristics of the clinical examination, as well as other test results, such as cone beam computed tomography, should be compared to establish a final diagnosis and to make decisions about treatment.

\section{CONCLUSION}

From the applied methodology and obtained results, it may be concluded that: (1) a partial analysis of filling quality or periapical area provides less information than unedited radiographic images for endodontic diagnoses; (2) root filling quality substantially affects periapical diagnoses and retreatment decisions.

\section{REFERENCES}

1- Al-Ali K, Marghalani H, Al-Yahya A, Omar R. An assessment of endodontic re-treatment decision-making in an educational setting. Int Endod J. 2005;38:470-6.

2- Ashley M, Harris I. The assessment of the endodontically treated tooth. Dent Update. 2001;28:247-52.

3- Balto HA, Al-Madi EM. A comparison of retreatment decisions among general dental practitioners and endodontists. J Dent Educ. 2004;68:872-9.

4- Bodanezi A, Munhoz EA, Bernadineli N, Capelozza ALA, Moraes UG, Bramante CM. Radiographic analysis of root canal fillings: influence of two sealers on the perception of voids. Braz Dent J. 2010;21:142-7.

5- Boucher Y, Matossian L, Rilliard F, Machtou P. Radiographic evaluation of the prevalence and technical quality of root canal treatment in a French subpopulation. Int Endod J. 2002;35:22938.

6- Chugal NM, Clive JM, Spångberg LSW. Endodontic infection: some biologic and treatment factors associated with outcome. Oral Surg Oral Med Oral Pathol Oral Radiol Endod. 2003;96:81-90. 7- Cotti E, Vargiu P, Dettori C, Mallarini G. Computerized tomography in the management and follow-up of extensive periapical lesion. Endod Dent Traumatol. 1999;15:186-9.

8- Eckerbom M, Magnusson T. Evaluation of technical quality of endodontic treatment - reliability of intraoral radiographs. Endod Dent Traumatol. 1997;13:259-64.

9- Estrela C, Leles CR, Hollanda ACB, Moura MS, Pécora JD. Prevalence and risk factors of apical periodontitis in endodontically treated teeth in a selected population of Brazilian adults. Braz Dent J. 2008;19:34-9.

10- Lin IM, Skribner JE, Gaengler P. Factors associated with endodontic treatment failures. J Endod. 1992;18:625-7.

11- Luiz RR, Costa AJL, Nadanovsky P. Epidemiologia e bioestatística na pesquisa odontológica. São Paulo: Atheneu; 2005. 12- Molven O, Halse A, Fristad I, MacDonald-Jankowski D. Periapical changes following root-canal treatment observed 20-27 years postoperatively. Int Endod J. 2002;35:784-90.

13- Nair PN. On the causes of persistent apical periodontitis: a review. Int Endod J. 2006;39:249-81.

14- Nair PN, Sjögren U, Figdor D, Sundqvist G. Persistent periapical radiolucencies of root-filled human teeth, failed endodontic treatments, and periapical scars. Oral Surg Oral Med Oral Pathol Oral Radiol Endod. 1999;87:617-27.

15- Nakamura DH, Garcia RB, Bramante CM, Moraes IG, Bernadineli N. Sealing ability of cements in root canals prepared for intrarradicular posts. J Appl Oral Sci. 2006;14:224-7.

16- Nicholls E. Assessment of the periapical status of pulpless teeth. Br Dent J. 1963;114:453-9.

17- Orstavik D, Kerekes K, Eriksen HM. The periapical index: a scoring system for radiographic assessment of apical periodontitis. Endod Dent Traumatol. 1986;2:20-34.

18- Pagonis TC, Fong CD, Hasselgren G. Retreatment decisions - a comparison between general practitioners and endodontic postgraduates. J Endod. 2000;26:240-1. 
19- Patel S, Dawood A, Mannocci F, Wilson R, Pitt Ford T. Detection of periapical bone defects in human jaws using cone beam tomography and intraoral radiography. Int Endod J. 2009;42:50715.

20- Rawski AA, Brehmer B, Knutsson K, Petersson K, Reit C, Rohlin $M$. The major factors that influence endodontic retreatment decisions. Swed Dent J. 2003;27:23-9.

21- Reit C, Gröndahl HG. Application of statistical decision theory to radiographic diagnosis of endodontically treated teeth. Scand J Dent Res. 1983;91:213-8.

22- Reit C, Gröndahl HG. Management of periapical lesions in endodontically treated teeth. A study on clinical decision making. Swed Dent J. 1984;8:1-7.

23- Reit C, Hollender L. Radiographic evaluation of endodontic therapy and the influence of observer variation. Scand J Dent Res. $1983 ; 91: 205-12$.
24- Vandenberghe B, Jacobs R, Yang J. Detection of periodontal bone loss using digital intraoral and cone beam computed tomography images: an in vitro assessment of bony and/or infrabony defects. Dentomaxillofac Radiol. 2008;37:252-60.

25- Van Nieuwenhuysen JP, Aouar M, D'Hoore W. Retreatment or radiographic monitoring in endodontics. Int Endod J. 1994;27:7581.

26- Weiger R, Hitzler S, Hermle G, Löst C. Periapical status, quality of root canal fillings and estimated endodontic treatment needs in an urban German population. Endod Dent Traumatol. 1997; 13:69-74.

27- Whaites E. Essentials of dental radiography and radiology. London: Churchill Livingstone; 2002.

28- Wolcott J, Meyers J. Endodontic re-treatment or implants: a contemporary conundrum. Compend Contin Educ Dent. 2006;27:104-10. 